\title{
Double sampling for stratification for the monitoring of sparse tree populations: the example of Populus euphratica Oliv. forests at the lower reaches of Tarim River, Southern Xinjiang, China
}

\author{
Tzeng Yih Lam • Christoph Kleinn • \\ Bodo Coenradie
}

Received: 15 May 2009 / Accepted: 21 April 2010 / Published online: 18 May 2010

(C) The Author(s) 2010. This article is published with open access at Springerlink.com

\begin{abstract}
Desertification is a pressing issue in the dry Tarim River basin, which is under anthropogenic stresses. In this study, double sampling for stratification (DSS) is employed to inventory Populus euphratica Oliv. forests in the lower reaches of the Tarim River Basin in Xinjiang, China. The two objectives were evaluating DSS as a sampling technique for monitoring desertification and generating baseline information for permanent observation. Here, DSS consists of two phases: in
\end{abstract}

T. Y. Lam · C. Kleinn

Burckhardt-Institute, Georg-August-Universität

Göttingen, Büsgenweg 5, 37077 Göttingen, Germany

C. Kleinn

e-mail: ckleinn@gwdg.de

B. Coenradie

Department of Geoinformation Processing

for Landscape and Environmental Planning,

Institute of Landscape Architecture

and Environmental Planning,

Technical University Berlin, Straße des 17. Juni 145,

10623 Berlin, Germany

e-mail: coenradie@dd-berlin.de

Present Address:

T. Y. Lam $(\varangle)$

Department of Forest Ecosystems and Society,

College of Forestry, Oregon State University,

321 Richardson Hall, Corvallis, OR 97331, USA

e-mail: forestlam@fastmail.fm phase 1 , crown cover is observed on a large sample of plots on a high resolution satellite image, and these photo-plots are stratified into five crown cover strata. Phase 2 is a stratified random sample from these photo-plots and the sampled plots are field observed. Approximately $32 \%$ of the study area is without $P$. euphratica trees. As expected, estimated mean poplar tree density and basal area increase with crown cover. DSS takes advantages of stratification (fieldwork efficiency and statistical precision) without the need for a priori strata delineation. It proves feasible for inventory the sparse poplar population and holds promise for the assessment of trees outside the forest, where density varies considerably and pre-stratification is intractable. It can be integrated into permanent observation systems for monitoring vegetation changes.

Keywords Desertification - Probabilistic sampling • Trees outside forest • Diversifolious poplar $\cdot$ High resolution satellite image . Remote sensing

\section{Introduction}

Desertification is one of the most serious current environmental challenges in the context of global change. Approximately one third of the global land surface is under threat of desertification 
(Li 2004). The United Nations Convention to Combat Desertification (UNCCD) defines desertification to be land degradation in arid, semiarid, and dry subhumid areas resulting from various factors (UNEP 1997). Causes of desertification have been thoroughly researched and documented in the past decades: from a metaanalysis of 132 local desertification case studies in five continents, Geist (2005) concluded that desertification is mostly attributable to the interaction of factors such as agricultural activities, infrastructure extension, and increasing aridity due to changes in climatic conditions.

China is among those countries that are most severely affected by desertification (Zhou et al. 2003). Recognizing this threat, the Chinese government has initiated intensive scientific and technical research by mobilizing huge financial resources as early as in the 1950s and has began nationwide desertification assessments since the mid-1980s (Sun and Fang 2001; Yang et al. 2005). By the late 1990s, the Chinese Committee for Implementing the UNCCD estimated that desertification of different intensities has affected as much as $79.1 \%$ of the total area of arid, semiarid, and dry subhumid regions, corresponding to 2.62 million $\mathrm{km}^{2}$ or about $27.3 \%$ of the country's total land surface (CCICCD 1997; Lu 2001). Three desertification categories-slight, medium, and severe-were distinguished and accounted for $36.3 \%, 24.4 \%$, and $39.3 \%$ of the total affected area, respectively (CCICCD 1997). However, Zhu and $\mathrm{Wu}$ (1998) claimed that this figure was inflated by including areas of desert, frozen, and melting land; instead, they produced a total estimate of 0.86 million $\mathrm{km}^{2}$. $\mathrm{Hu}$ (2003) estimated that 1.74 million $\mathrm{km}^{2}$ would be affected by the early 2000s. The considerable discrepancies in the estimates are largely due to inconsistencies in in- dicator systems, definitions of desertification, and assessment tools. Various studies estimated the annual affected rate of desertification in China over the past decades. The mean annual rate of desertification increases dramatically as indicated in Table 1.

Despite potential methodological inconsistencies and lack of precision estimates that would allow for significance tests, the assessment figures from CCICCD are mostly cited in official documents and literature because the data are consistent with the UNCCD definition and based on extensive field work (see Lu 2001; Wu 2001; Zhou et al. 2003; Yang et al. 2005).

To efficiently assess indicators of desertification, clear definitions and adequate monitoring tools are required to meet the challenge of providing information on both large and small areas (e.g., for nationwide and local assessment) of vegetation cover types that are usually sparse and scattered. To accomplish such a task, Huang and Siegert (2006) suggested a multiscale remote sensing-based monitoring approach in which lowresolution images were used for monitoring largearea processes, and then higher resolution images were used for monitoring "hotspots" of change. China, with large areas prone to desertification and limited access to many remote areas, particularly lends itself to a satellite image-based assessment on both national and local levels (Yang et al. 2005). On this basis, many criteria and indicator systems for desertification assessment have been developed for various parts of China such as the Hexi area of Gansu Province and $\mathrm{Mu}$ Us Sandy Land (Ma et al. 1996; Wu et al. 1997; Gao et al. 1998; Wang et al. 2003). FAO (1983) provided detailed mapping procedures using both remotely sensed data and field plots, thus emphasizing both the importance of ground data for the verification
Table 1 Estimated

annual area newly affected by desertification in China over the past decades

\begin{tabular}{lll}
\hline Period & Source & $\begin{array}{l}\text { Estimated annual area } \\
\text { newly affected } \\
\text { by desertification, } \mathrm{km}^{2}\end{array}$ \\
\hline 1950s to mid-1970s & Zhu (1985) & 1,560 \\
1970 s to 1980s & Zhu and Wang (1990) & 2,100 \\
1980s to mid-1990s & CCICCD (1997) & 2,460 \\
Early twenty-first century & Hu (2003) & 3,436 \\
\hline
\end{tabular}


of image interpretation and the collection of data that cannot be directly derived from remote sensing imagery. When developing indicator systems for monitoring desertification, Gao et al. (1998) established 159 randomly selected square plots of $1 \mathrm{~km}^{2}$ each in the provinces of Gansu, Ningxia, and Inner Mongolia for field research.

Double sampling for stratification is one of the many techniques that lay out field plots in a statistically rigorous manner and conform to probabilistic sampling; there are many advantages to do so. It incorporates the observation of ancillary variables to enhance sampling and fieldwork efficiency. It has been applied in many large-area forest inventories such as the Forest Inventory and Analysis (FIA) program in the United States. Very often, in the context of monitoring natural resources at a landscape level, the design is applied in conjunction with remotely sensed data to allow observing ancillary variables at a relatively low cost (see Bickford 1952; Bickford et al. 1963; Chojnacky 1998). To the best knowledge of the authors, double sampling for stratification has not yet been applied for the inventory of tree resources outside forests in general nor specifically in the context of assessing the scattered tree resource in desertification monitoring programs.

This study applied double sampling for stratification to estimate growing stock and related attributes of Tugai forests in the lower reaches of the Tarim River Basin in Xinjiang Uyghur Autonomous Region of the People's Republic of China. The study was embedded in the research project EVASTar, initiated by the Institute of Landscape Architecture and Environmental Planning of the Technical University of Berlin. The project focused on monitoring the vitality of the Tugai forests using high-resolution (HR) and very-high-resolution (VHR) satellite data and had been implemented in cooperation with the Xinjiang University (Institute of Landscape Architecture and Environmental Planning 2007). The objectives of this paper are in support of the overall goals of that project: (1) evaluating the application of double sampling for stratification in a desertification monitoring program and in monitoring of scattered tree population in general and (2) generating a baseline for a permanent observation program in that particular region.

\section{Materials and methods}

Materials

The descriptions of our study area are largely drawn from the comprehensive information provided by Chen et al. (2006) and Zhang et al. (2005). The Tarim River Basin in southern Xinjiang has seen intensive confrontation between environmental protection and economic development over the past five decades. The Tarim River, with a total length of $1,321 \mathrm{~km}$, is the longest arid and intercontinental river in the world, running across the northern and eastern rim of the Taklamakan Desert (Fig. 1). Ambitious agricultural development and land reclamation projects implemented by the Chinese government in the early 1960s led to construction of dams such as the Daxihaizi Reservoir that disrupted the stream-flow to the lower reaches. Exploitation of natural resources for fuel, excessive diversion of freshwater, increases of human population, and irrigation-induced salinity have caused major environmental degradation and the advancement of desertification. The lower reaches of the Tarim River Basin-a stretch of $321 \mathrm{~km}$-starts from the Daxihaizi Reservoir in Yuli County and ends in the Lop Nor lake in the Ruoqiang County. Since the 1970s, this part of the river has seen the groundwater level drop from 3-5 to 8-12 m below the surface and the drying up of the two terminal lakes, Lop Nor and Taitema Nor.

Inevitably, the distribution and the diversity of plant communities along the river have been affected by this ongoing heavy human intervention and decreasing groundwater supply. The total area affected by desertification has increased from 1,371 to $1,494 \mathrm{~km}^{2}$ between 1959 and 1991, while the areas of forest and grassland have decreased by 2,000 and $8,500 \mathrm{~km}^{2}$, respectively. The "Green Corridor" formed by the Populus euphratica plant community between the Taklamakan Desert and the Kuruk Desert that snaked along the lower reaches of the Tarim River is heavily affected by progressing desertification. The National Highway No. 218 running through the "Green Corridor" has suffered from increased sand encroachment because the area of the protective $P$. euphratica 


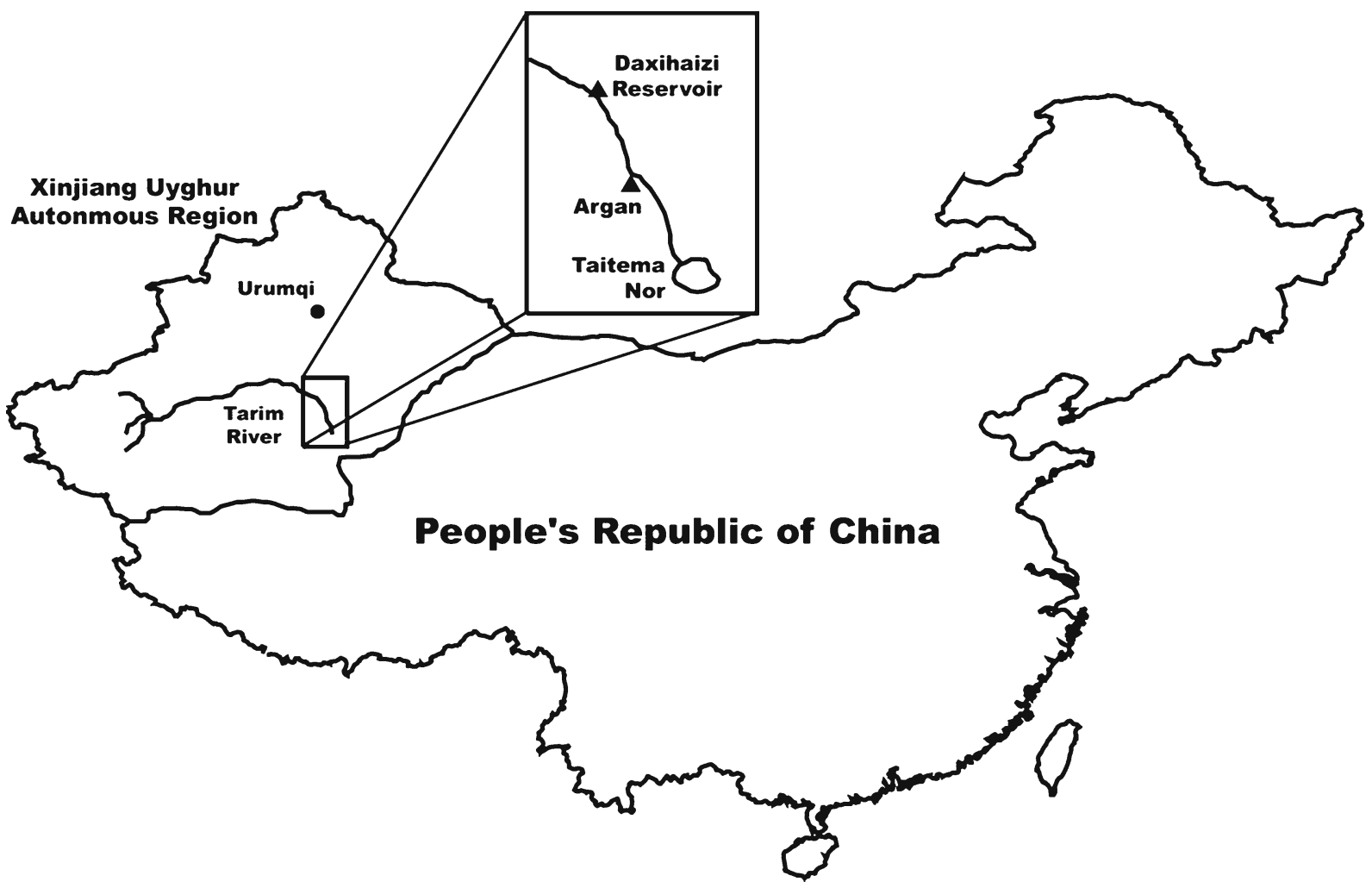

Fig. 1 Location of the study sites at Argan, along the lower reaches of Tarim River Basin at Xinjiang Uyghur Autonomous Region in People's Republic of China

plant community is decreasing. Recognizing the issue, the Chinese Central Government in year 2000 granted a total of 10.7 billion Chinese Yuan (RMB) to an emergency project that artificially recharged the Tarim River to raise the groundwater level and to ecologically restore the local vegetation.

The current study was carried out in the area around Argan, an abandoned village at the lower reaches of the Tarim River $\left(40^{\circ} 08.80^{\prime} \mathrm{N}, 88^{\circ} 21.50^{\prime}\right.$ E; see Fig. 1) in August 2005. The study sites consist of two large sections that were delineated for monitoring; one section is located mainly to the southwest of Argan and the other to the southeast (Fig. 2a). The area encompassed by the north and south sections are 105.9 and 116.2 ha, respectively. The National Highway No. 218 crosses the two sections, thus facilitating fieldwork in the study sites. The terrain is a flat floodplain with slopes up to $3 \%$ and an elevation of $816-852 \mathrm{~m}$. The environment is characterized as extremely dry desert climate with long hot summers. The average annual precipitation is $<50 \mathrm{~mm}$; however, potential annual evaporation is estimated to be between 2,500 and 3,000 $\mathrm{mm}$. The average January, July, and annual temperatures are $-12.6^{\circ} \mathrm{C}, 27.8^{\circ} \mathrm{C}$, and $11.7^{\circ} \mathrm{C}$, respectively, whereas the daily minimum and maximum temperatures could reach $-27.5^{\circ} \mathrm{C}$ and $43.6^{\circ} \mathrm{C}$, respectively (Wang and Fan 1998).

There are 24 common plant species recorded in the surroundings of Argan. By far, the most abundant tree species in this region is the diversifolious poplar, P. euphratica Oliv., known for its capability to survive under the harshest site conditions. Other common shrub species include Tamarix ramosissima Ledeb., Tamarix hispida Willd., Tamarix leptostachys B., Elaeagnus angustifolia L., and Karelina caspica (Pall.) Less. These species exhibit a high tolerance to salinity, dryness, and heat and have important ecological functions in fixation of sand dunes, in underground water table preservation, and thus in influencing 

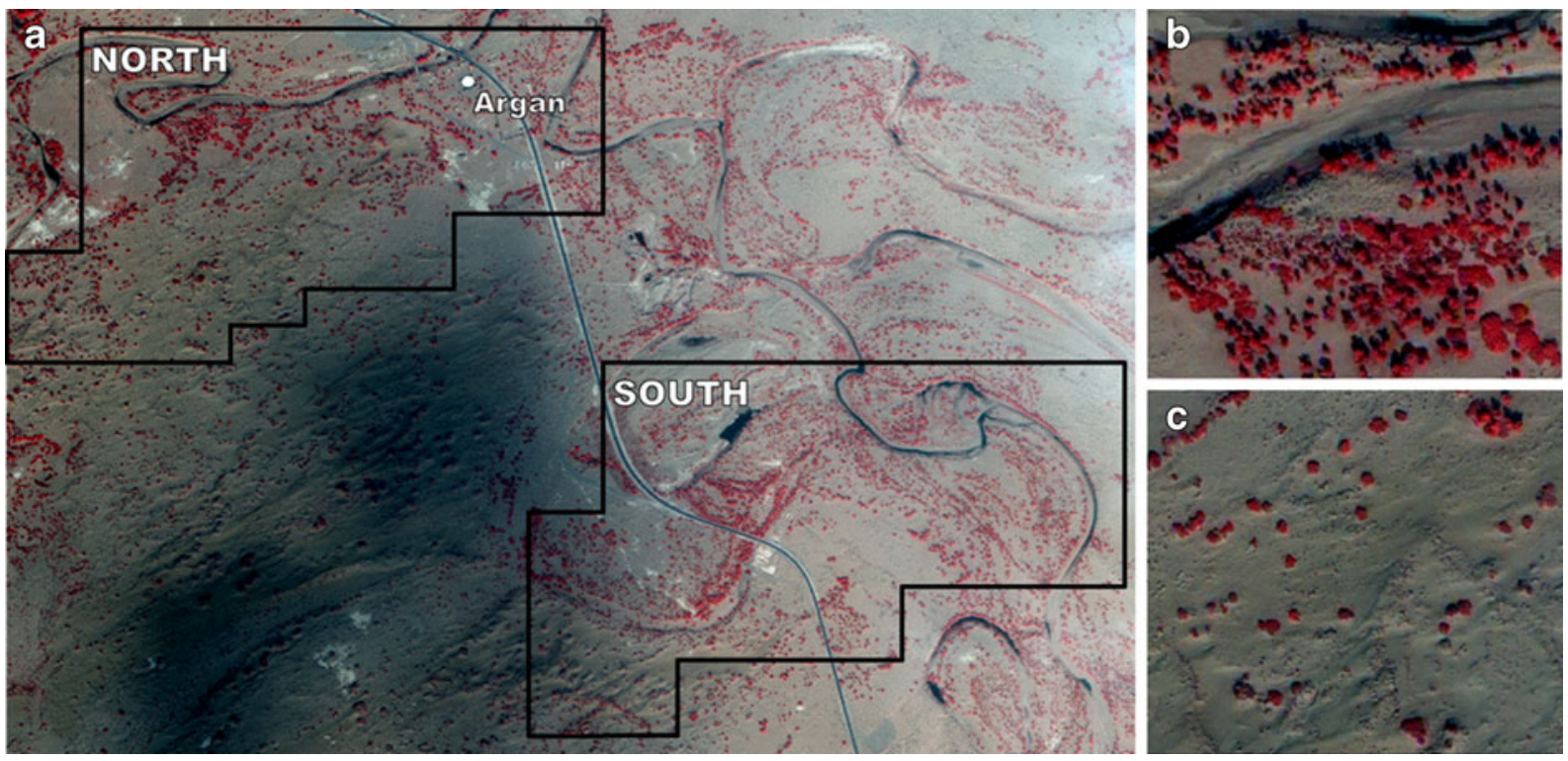

Fig. 2 Quickbird false color (infrared) satellite composite showing (a) locations of the North $\left(40^{\circ} 08.42^{\prime} \mathrm{N}\right.$ to $40^{\circ} 08.90^{\prime}$ $\mathrm{N}$ and $88^{\circ} 20.57^{\prime} \mathrm{E}$ to $\left.88^{\circ} 21.70^{\prime} \mathrm{E}\right)$ and South $\left(40^{\circ} 07.87^{\prime} \mathrm{N}\right.$ to $40^{\circ} 08.42^{\prime} \mathrm{N}$ and $88^{\circ} 21.52^{\prime} \mathrm{E}$ to $88^{\circ} 22.67^{\prime} \mathrm{E}$ ) sections relative to Argan, the Tarim River, and the National Highway

the progress of desertification. In this study, we focused data collection solely on P. euphratica, as it is the only tree species that can form forest structures along the lower reaches of the Tarim River.

An environmental gradient, particularly the groundwater level, is approximately perpendicular to the Tarim River and influences the plant communities and structures. Particularly, the distribution of $P$. euphratica exhibits spatial heterogeneity-from dense clustering along the former riverbank to sparse single-tree distribution toward the desert. The two sections were purposefully delineated to reflect the gradient in the density and pattern of $P$. euphratica, as clearly shown on the satellite image (Fig. 2b, c). This gradient poses a challenge for choosing an appropriate sampling design.

\section{Methods}

The heterogeneous vegetation cover as shown in Fig. 2 intuitively suggests stratification into vegetation density strata as a suitable sampling de-
No. 218, (b) relatively dense $P$. euphratica forests along the river bank of Tarim River, and (c) more sparsely distributed $P$. euphratica trees on the fringe of the Taklamakan Desert. $P$. euphratica crowns can be recognized as the bright red objects

sign element. However, prestratification is hardly tractable because the boundaries between strata cannot be clearly delineated. Double sampling for stratification (DSS) is a sampling strategy that employs stratification without requiring a priori delineation of strata; the strata sizes are estimated in the course of a two-phase sampling process. Therefore, it is suitable for situations like the one encountered here, where stratification is suspected to be efficient but strata cannot easily be delineated in advance.

Double sampling, also known as two-phase sampling, is a class of sampling techniques that was originally proposed by Neyman (1938), where in the first phase (phase 1), a large sample of an auxiliary variable is taken and, in the second phase (phase 2), target variable is measured on a smaller sample. The relationship between auxiliary and target variable is then utilized by the estimator to produce a more precise estimate of the target variable. Double sampling for stratification is a specific variant of double sampling: the auxiliary variable observed in the first phase is the categorical variable "stratum," and in phase 2 a subsample 
is taken from each stratum to observe the target variables.

In general, double sampling strives to improve the estimation of an expensive-to-measure target variable through a large sample of easy-andcheap-to-measure auxiliary variables. The performance of double sampling depends on several factors: the relative costs of phase 1 to phase 2 samples, the extent to which the total variance is reduced by stratification (Bickford 1952), and the correlation between the ancillary and the target variable. Under favorable conditions, double sampling is a powerful tool that can-for a given cost-reduce the error variance of the target variable considerably compared to other sampling designs such as simple random sampling (Neyman 1938).

\section{Phase 1}

A Quickbird satellite image, which is a VHR satellite datum, taken at year 2004 (1 year before field sampling) was used for phase 1 sampling in which photo-plots were established. The image was first geometrically corrected, and then a pan-sharpened false color (infrared) image was produced by data fusion techniques from the multispectral (2.4-m spatial resolution) and panchromatic $(0.6 \mathrm{~m})$ channels of Quickbird imagery. Zhang (2002) provided discussion on the data fusion techniques, particularly for high-resolution satellite data, and detailed procedures are documented in the final report of the EVASTar project (Institute of Landscape Architecture and Environmental Planning 2007).

Crown cover (CC) was used as the easy-toobserve auxiliary variable, as it is closely related to tree density. Additionally, change in vegetation cover is often used as a direct or indirect indicator of the extent of desertification in China (see also Ma et al. 1996; Gao et al. 1998; Wang et al. 2003; Yang et al. 2005; Huang and Siegert 2006). Since $P$. euphratica was the species of interest, the goal was to produce a $P$. euphratica crown cover map (hereafter referred to as poplar crown cover mask). While automatic classification clearly distinguished vegetation from non-vegetation, by itself, it could not clearly distinguish $P$. euphratica from other vegetation. Therefore, a two-step classification approach was used: first, automatic classification distinguished vegetation from other cover with the normalized difference vegetation index, and second, the differentiation of $P$. euphratica crown cover from shrub and grass cover was done by visual interpretation and manual separation.

A moving window approach was used for automatic preliminary classification: centered at a pixel, a $20-\mathrm{m}$ radius circle (i.e., window) was drawn over the mask; $20 \mathrm{~m}$ was used as it was the size of a phase 1 photo-plot. The crown cover percentage for the central pixel was estimated as the proportion of the window area covered by the poplar mask. Then, the circular window was subsequently moved to the neighboring pixels and so forth (a subset of circular windows is depicted in Fig. 3). Eventually, the crown cover value was determined for every (central) pixel using a 20-m radius circle as reference area. For the pixels on the boundary of the study sites, the edge effect was not taken into account; the part of the window outside the study site boundary was included in crown cover observation (Fig. 3).

A north-south oriented square grid of $100 \mathrm{~m}$ was superimposed over the Quickbird image and the poplar crown cover mask for each of the north and south sections (Fig. 4). Each grid point, corresponding to a pixel on the image, was sampled as the center of a phase 1 photo-plot having a radius of $20 \mathrm{~m}$ (covering an area of $0.126 \mathrm{ha}$ ). Thus, a photo-plot was essentially a window, and its crown cover percentage was estimated from the moving window approach (Fig. 3). This resulted in a total of 275 photo-plots, each assigned to one of five strata according to CC percentage $(0 \%,>0$ $10 \%,>10-30 \%,>30-50 \%$, and $>50 \%$ ). Strata definitions were based on previous field experience and structural characteristics of the forest stands; most of the area was covered by scattered trees, and there were very few denser groups of trees.

\section{Phase 2}

In phase 2, a subsample of phase 1 photo-plots was taken, and field plots were established to observe the target variables such as tree density and size. Considering the time constraints, the number of 
Fig. 3 Poplar crown cover mask with color gradients (light to dark) corresponding to P. euphratica crown cover percentage. The circles represent a subset of circular windows (or phase 1 photo-plots) at 100-m spacing. The enclosed areas are the two study sites

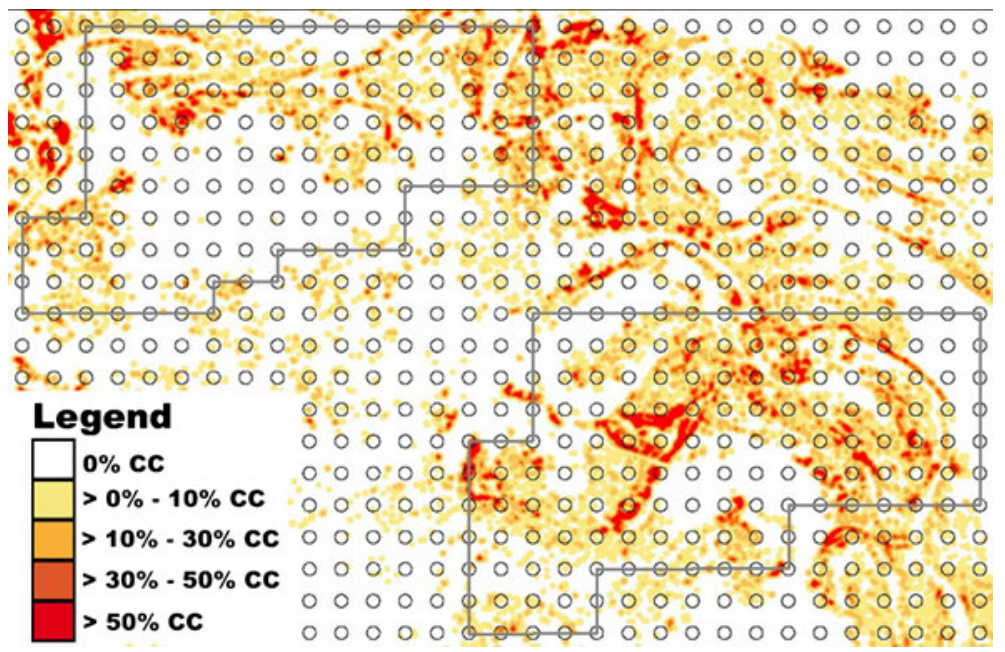

field crews, and the overall field conditions, a sample size of $n=66$ was defined for phase 2 sampling. No field plots were allocated to stratum 1 as it was clear from the satellite image interpretation that trees were absent; here, we assumed that the classification of the poplar crown cover mask was perfect and any error negligible. The 66 ground plots were, therefore, allocated to strata 2 to 5 proportional to the stratum size as estimated from phase 1 sampling. Phase 2 stratum size was estimated as the proportion of $n_{h}$ to 188 for $h=2$, ..., 5 (explained in Table 3 ). Within each stratum, the field plots were randomly selected from the set of photo-plots. Figure 5 shows the locations of the ground plots for strata 2 to 5 .
Owing to the different tree density across strata, a larger field plot size (circular plot with a radius of $r=20 \mathrm{~m}$, that is, $0.126 \mathrm{ha}$ ) was used for strata 2 and 3 than for strata 4 and 5 ( $r=$ $15 \mathrm{~m}$, that is, $0.071 \mathrm{ha}$ ). The following tree attributes were recorded: diameter at breast height (dbh), total height (ht), height to base of live crown (htlive), crown width (cw), and live or dead status. Minimum tree height was defined to be $1.3 \mathrm{~m}$. Crown length (the difference between total height and height to the base of live crown) and crown ratio (ratio of crown length to total height) were calculated from these measurements. Indicators of tree health such as percent leaf loss and crown form were measured, and the analyses were
Fig. 4 Photo-plots from phase 1 in the double sampling for stratification approach. Each photo-plot was assigned to a stratum according to its $P$. euphratica crown cover (CC)

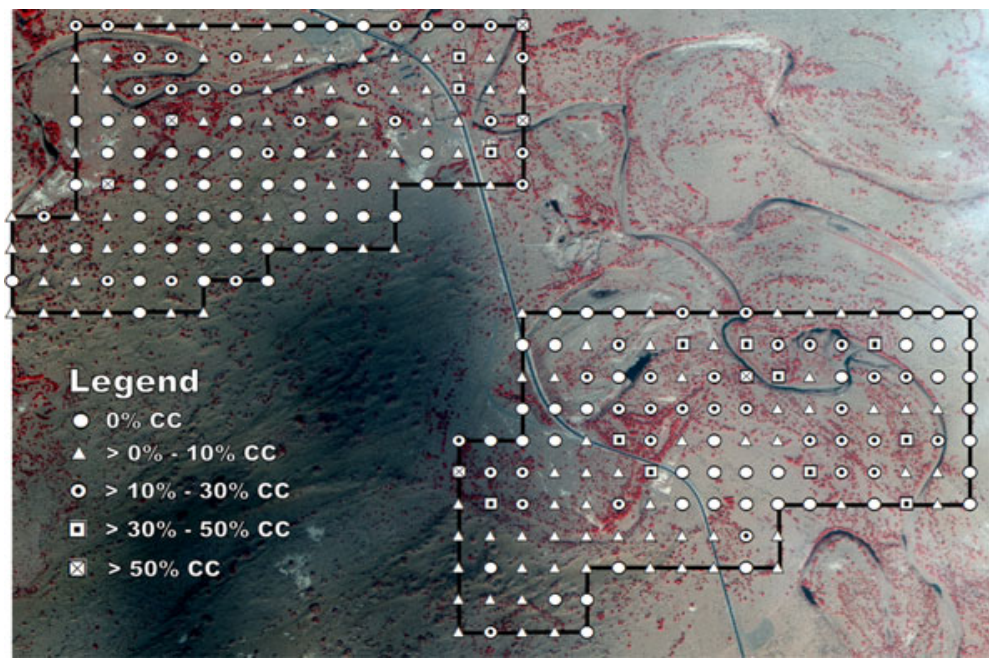


Fig. 5 Locations of the field plots selected randomly from the photo-plots of each stratum

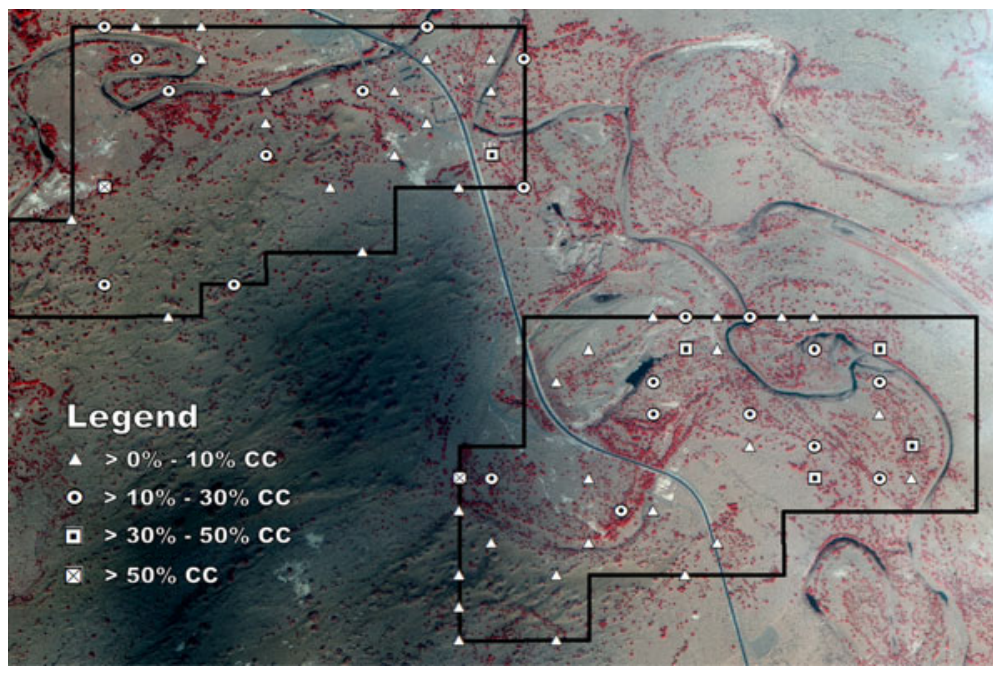

incorporated in the final report of the research project EVASTar (Institute of Landscape Architecture and Environmental Planning 2007).

\section{Estimators}

Estimators for double sampling for stratification have been investigated and documented by many, some in relation to theoretical development and others to application in large-area forest inventory (Cochran 1977; Scott and Bechtold 1995; Williams and Schreuder 1995; Chojnacky 1998; Williams 2001). The estimators used here are adapted from Lohr (1999) and Thompson (2002), and they assume simple random sampling (SRS) in both phases. However, we applied systematic sampling (SyS) in phase 1 of our study. Yet in the absence of design based variance estimators for systematic sampling, we follow the frequently employed convention in forest inventory and use the SRS estimator framework that is known to produce conservative variance estimates.

Notation is as follows:

$L \quad$ number of crown cover strata $(L=5)$

$A$ total area of the study sites $(A=$ 222.1 ha)

$a_{h} \quad$ estimated area of stratum $h$

$n$ total number of photo-plots in phase 1 $(n=275)$

$n_{h} \quad$ number of phase 1 photo-plots in stratum $h$ $m$ total number of phase 2 field plots $(m=$ 66)

$m_{h} \quad$ number of phase 2 field plots in stratum $h$

$y_{h j k} \quad$ observed tree attribute $y$ (e.g., tree basal area) for tree $k$ on field plot $j$ in stratum $h$

$y_{h j} \quad$ observed tree attribute $y$ per unit area for field plot $j$ in stratum $h$

$\bar{y}_{h} \quad$ estimated mean tree attribute $y$ per unit area in stratum $h$

$\bar{y} \quad$ estimated mean tree attribute $y$ per unit area for the study sites

$\hat{\tau}_{h} \quad$ estimated total of attribute $y$ for stratum $h$

$\hat{\tau} \quad$ estimated total of attribute $y$ for the study sites

$\widehat{\operatorname{var}}\left(\bar{y}_{h}\right)$ estimated variance of the estimated mean for stratum $h$

$\widehat{v a r}(\bar{y})$ estimated variance of the estimated mean for the study sites

$\widehat{\operatorname{var}}(\hat{\tau})$ estimated variance of the estimated total for the study sites

$E F_{h j} \quad$ expansion factor for field plot $j$ in stratum $h$

where, $h=1, \ldots, L ; j=1, \ldots, m_{h}$

For estimation, the per-plot observations are first converted to per-hectare observations by means of plot-size-dependent expansion factors EF. For strata 2 and 3, the expansion factor is 7.9, and for strata 4 and 5, it is 14.1. The extrapolated 
tree attribute per hectare for field plot $j$ in stratum $h$ is

$y_{h j}=\sum_{k} y_{h j k} \cdot E F_{h j}$,

from which the estimated mean per hectare for stratum $h$ is derived as

$\bar{y}_{h}=\frac{1}{m_{h}} \sum_{j=1}^{m_{h}} y_{h j}$.

the estimated mean per hectare for the study sites is

$\bar{y}=\sum_{h=1}^{L} \frac{n_{h}}{n} \bar{y}_{h}$,

and the estimated total for the study sites

$\hat{\tau}=A \bar{y}$

Note that the estimated mean tree attribute $y$ per hectare for stratum 1 is 0 (i.e., $\bar{y}_{1}=0$ ), since there are no trees in a stratum with $0 \%$ crown cover. Nonetheless, it is included in the calculation of Eqs. 3 and 4 because estimations for the entire population (including the empty stratum 1) were desired. Otherwise, we would have to redefine the population of interest to exclude empty areas, which is difficult given the sparse distribution of P. euphratica.

The area of stratum $h$ is estimated from the phase 1 samples by

$a_{h}=A \frac{n_{h}}{n}$,

and the estimated total tree attribute $y$ for each stratum is then

$\hat{\tau}_{h}=a_{h} \bar{y}_{h}$.

The estimated variance of the estimated mean tree attribute $y$ for stratum $h$ is

$\widehat{\operatorname{var}}\left(\bar{y}_{h}\right)=\frac{\sum_{j=1}^{m_{h}}\left(y_{h j}-\bar{y}_{h}\right)^{2}}{m_{h}\left(m_{h}-1\right)}$.

Averaging the over all strata and without the finite population correction (fpc), the estimated variance of the estimated mean for the study sites is

$$
\begin{aligned}
\widehat{\operatorname{var}}(\bar{y})= & \sum_{h=1}^{L} \frac{n_{h}-1}{n-1} \frac{n_{h}}{n} \widehat{\operatorname{var}}\left(\bar{y}_{h}\right) \\
& +\frac{1}{n-1} \sum_{h=1}^{L} \frac{n_{h}}{n}\left(\bar{y}_{h}-\bar{y}\right)^{2} .
\end{aligned}
$$

The estimated variance of the estimated total for the study sites is

$\widehat{\operatorname{var}}(\hat{\tau})=A^{2} \widehat{\operatorname{var}}(\bar{y})$,

and the estimated variance of the estimated total for each stratum is

$\widehat{\operatorname{var}}\left(\hat{\tau}_{h}\right)=a_{h}^{2} \widehat{\operatorname{var}}\left(\bar{y}_{h}\right)$.

The respective standard errors (SE) are the square root of Eqs. 7, 8, 9, and 10.

The coefficient of variation $(\mathrm{CV} \%)$, reflecting the relative variability between plots within a stratum, is estimated for each stratum by

$\mathrm{CV} \%=\frac{\sqrt{m_{h} \widehat{\mathrm{var}}\left(\bar{y}_{h}\right)}}{\bar{y}_{h}} \times 100 \%$.

The $95 \%$ confidence interval (CI) of an estimated mean tree attribute $y$ for stratum $h$ is

$95 \% \mathrm{CI}=\bar{y}_{h} \pm t_{1-\frac{\alpha}{2}, m_{h}-1} \cdot \sqrt{\widehat{\operatorname{var}}\left(\bar{y}_{h}\right)}$,

where $\alpha=0.05$ and $t_{1-\alpha / 2, m_{h}-1}$ is the $t$ value at $1-$ $\alpha / 2$ percentile of the Student's $t$-distribution with $m_{h}-1$ degrees of freedom.

The computation of $95 \%$ CI for the overall estimated mean tree attribute $y$ per ha $(\bar{y})$ requires the calculation of effective degrees of freedom (EDF). Since the sample sizes differ by stratum, the degrees of freedom for $\bar{y}$ cannot be easily computed as the summed of strata degrees of freedom. This issue is known as the Welch-Satterthwaite problem or the Fisher-Behrens problem. Satterthwaite (1946) provided an approximation of the EDF as

$$
\mathrm{EDF} \approx \frac{[\widehat{\operatorname{var}}(\bar{y})]^{2}}{\sum_{h=1}^{5} \frac{\left[\frac{n_{h}^{2}}{n^{2}} \widehat{\left.\operatorname{var}\left(\bar{y}_{h}\right)\right]^{2}}\right.}{m_{h}-1}}
$$

Thus, the $95 \% \mathrm{CI}$ for $\bar{y}$ is given as $\bar{y} \pm t_{1-\frac{\alpha}{2}}, E D F$. $\sqrt{\widehat{\operatorname{var}}(\bar{y})}$. Then, the $95 \% \mathrm{CI}$ for the total tree 
attribute $y$ over the entire area $(\hat{\tau})$ is obtained by multiplying the total area $(222.1 \mathrm{ha})$ with the lower and upper bound of the $95 \%$ CI for $\bar{y}$.

\section{Results}

\section{Populus euphratica forest structures}

There were a total of 996 P. euphratica trees sampled and measured, of which 866 trees $(86.9 \%)$ were classified as live trees and 130 were dead standing trees $(13.1 \%)$. Figure 6 depicts that the $P$. euphratica forests consist mainly of medium-sized trees with variable crown structure. The dbh distribution is right skewed with $50 \%$ of the sampled live trees less than $20 \mathrm{~cm}$ (Fig. 6a). In fact, there are only 17 sampled trees with dbh greater than $60 \mathrm{~cm}$ (maximum of $107.7 \mathrm{~cm}$ ). These large trees
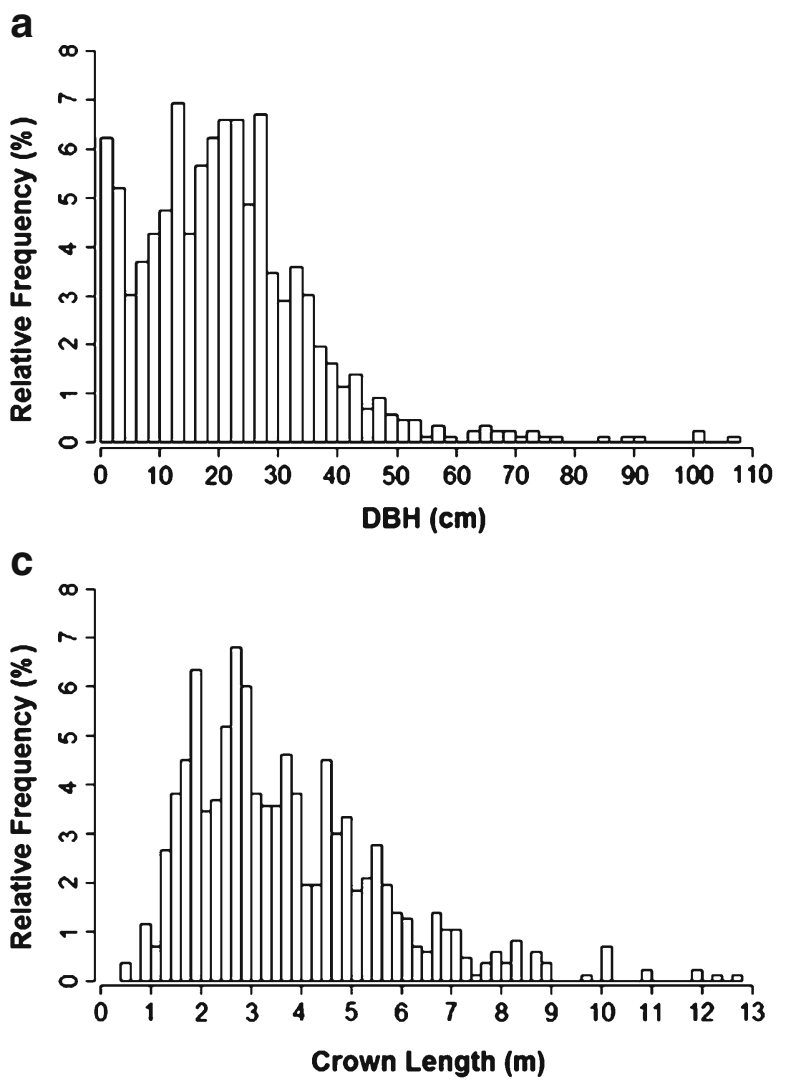

are generally isolated trees distributed across the landscape without regeneration underneath. Total height also shows a right-skewed trend with 50\% of the trees between 1.5 and $5.4 \mathrm{~m}$ (Table 2). The descriptive statistics of measured tree attributes do not differ greatly between strata with the exception of the maximum values for dbh, total height, crown width, and crown length.

The scatter plot of dbh and total height reveals that (1) dbh classes have a large range in total height, particularly at 40 to $50 \mathrm{~cm} \mathrm{dbh}$, and (2) trees with $\mathrm{dbh}>50 \mathrm{~cm}$ have a smaller mean total height than trees in the dbh range of about $30 \mathrm{~cm}$ (Fig. 6b). It was observed in the field that many large trees lost the top portion of the crown, and some of these trees formed patches of secondary crowns from dormant buds, which resulted in considerable variation in total height within a dbh class.
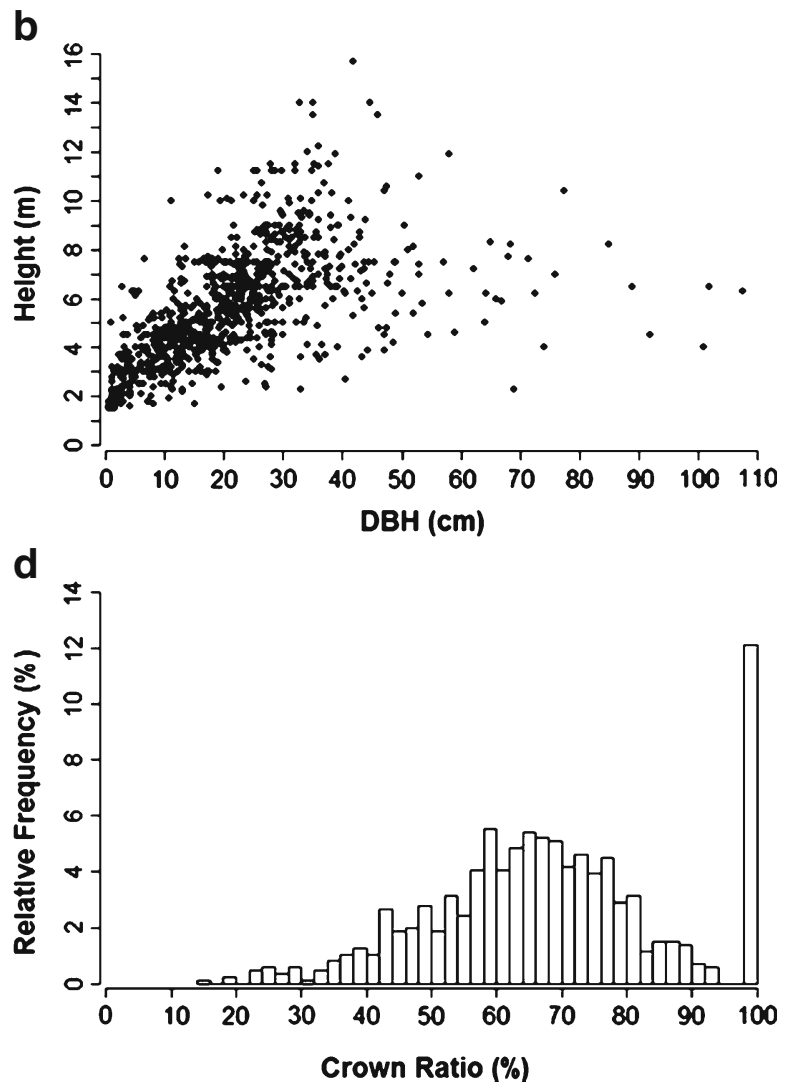

Fig. 6 (a) Frequency distribution of diameter at breast height $(\mathrm{cm})$, (b) scatter plot of dbh (cm) and total height (m), (c) frequency distribution of crown length $(\mathrm{m})$, and (d) crown ratio (\%) of all the sampled live trees 
Table 2 Basic descriptive statistics of the measured tree attributes for sampled live trees of each stratum and over the whole study sites

\begin{tabular}{|c|c|c|c|c|c|}
\hline & Minimum & Median & Maximum & Mean & Standard Deviation \\
\hline \multicolumn{6}{|c|}{ Diameter at breast height $(\mathrm{cm})$} \\
\hline Stratum 2 & 0.5 & 20.8 & 107.7 & 23.8 & 18.8 \\
\hline Stratum 3 & 0.5 & 20.0 & 85.0 & 20.6 & 13.2 \\
\hline Stratum 4 & 1.5 & 19.2 & 50.5 & 20.0 & 11.2 \\
\hline Stratum 5 & 1.0 & 0.5 & 47.0 & 19.4 & 11.7 \\
\hline Study sites & 0.5 & 20.0 & 107.7 & 21.5 & 15.0 \\
\hline \multicolumn{6}{|c|}{ Total height (m) } \\
\hline Stratum 2 & 1.5 & 5.0 & 11.9 & 5.1 & 2.0 \\
\hline Stratum 3 & 1.5 & 5.4 & 15.7 & 5.6 & 2.5 \\
\hline Stratum 4 & 1.7 & 5.7 & 12.2 & 6.1 & 2.5 \\
\hline Stratum 5 & 1.5 & 6.4 & 14.0 & 6.3 & 2.3 \\
\hline Study sites & 1.5 & 5.4 & 15.7 & 5.6 & 2.4 \\
\hline \multicolumn{6}{|c|}{ Height to base of live crown (m) } \\
\hline Stratum 2 & 0.0 & 1.6 & 5.0 & 1.7 & 1.1 \\
\hline Stratum 3 & 0.0 & 1.8 & 6.0 & 1.9 & 1.2 \\
\hline Stratum 4 & 0.0 & 1.6 & 5.0 & 1.9 & 1.2 \\
\hline Stratum 5 & 0.0 & 2.0 & 4.7 & 1.9 & 1.2 \\
\hline Study sites & 0.0 & 1.7 & 6.0 & 2.2 & 1.2 \\
\hline \multicolumn{6}{|c|}{ Crown width (m) } \\
\hline Stratum 2 & 1.0 & 3.7 & 10.1 & 3.9 & 1.8 \\
\hline Stratum 3 & 0.7 & 3.6 & 10.3 & 3.8 & 1.7 \\
\hline Stratum 4 & 1.0 & 3.6 & 6.6 & 3.9 & 1.4 \\
\hline Stratum 5 & 1.5 & 3.7 & 7.3 & 3.8 & 1.3 \\
\hline Study sites & 0.7 & 3.6 & 10.3 & 3.8 & 1.7 \\
\hline \multicolumn{6}{|c|}{ Crown length (m) } \\
\hline Stratum 2 & 0.4 & 3.2 & 8.4 & 3.4 & 1.5 \\
\hline Stratum 3 & 0.6 & 3.2 & 12.7 & 3.8 & 2.0 \\
\hline Stratum 4 & 0.5 & 3.5 & 8.9 & 4.2 & 2.0 \\
\hline Stratum 5 & 1.4 & 3.8 & 12.4 & 4.2 & 2.2 \\
\hline Study sites & 0.4 & 3.3 & 12.7 & 3.6 & 1.9 \\
\hline \multicolumn{6}{|c|}{ Crown ratio (\%) } \\
\hline Stratum 2 & 20.0 & 68.0 & 100.0 & 68.0 & 17.8 \\
\hline Stratum 3 & 25.0 & 66.0 & 100.0 & 67.7 & 18.3 \\
\hline Stratum 4 & 15.0 & 70.5 & 100.0 & 69.9 & 17.4 \\
\hline Stratum 5 & 30.0 & 65.0 & 100.0 & 65.2 & 18.7 \\
\hline Study sites & 15.0 & 67.0 & 100.0 & 68.2 & 18.0 \\
\hline
\end{tabular}

In general, the $P$. euphratica trees have small crown lengths but high crown ratios. The frequency distribution of crown length is right skewed with a mean of $3.6 \mathrm{~m}$, indicating that the majority of the trees have small crowns (Table 2). Only $6 \%$ of the sampled trees have a crown length larger than $7 \mathrm{~m}$ (Fig. 6c). On the other hand, the majority of the trees have crown ratios larger than $65 \%$. The small crown length but large crown ratio is due to the characteristics of the secondary crown. This crown is generally short but nonetheless resulted in a large crown ratio because total height is low due to the frequent dead or broken treetops. This is clearly depicted in the right panel of Fig. 7. However, there are some trees with well-developed and extensive crown structures as depicted in the left panel of Fig. 7.

Estimated tree attributes of $P$. euphratica forests

The distribution of photo-plots to the strata in phase 1 clearly indicates that the $P$. euphratica in the study sites are sparsely distributed. Stratum 2 ( $>0-10 \%$ crown cover) is estimated to cover 
Fig. 7 The left picture depicts a stand of $P$. euphratica trees with well-developed large crown structures, whereas the right picture depicts a tree with dead and broken top and re-establishment of secondary crown
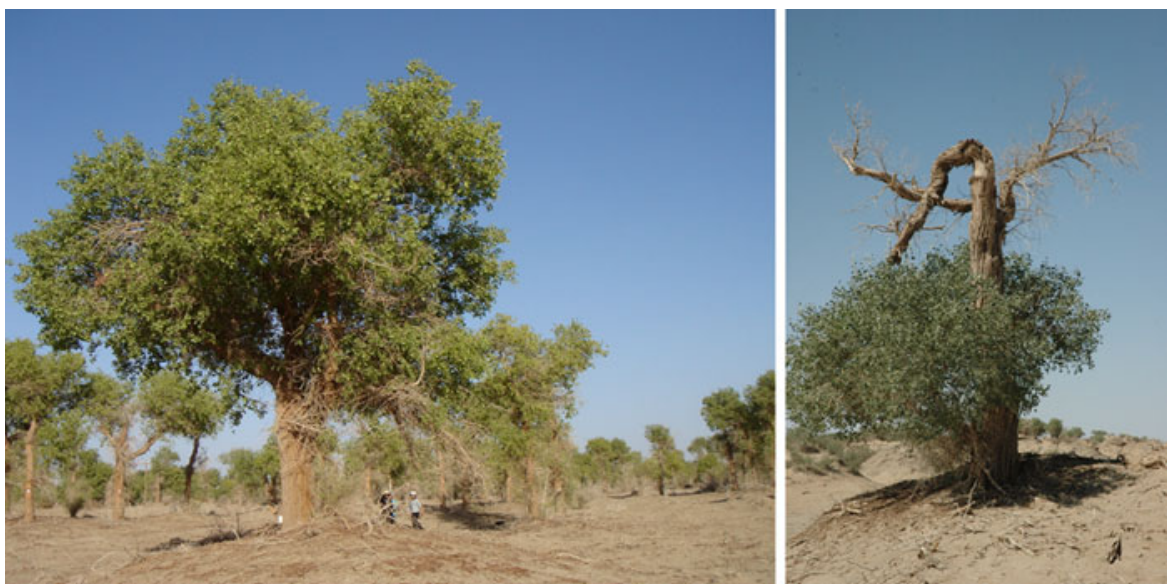

91.26 ha, constituting approximately $41.1 \%$ of the total area of the study sites, and stratum $1(0 \%$ crown cover) occupies 70.26 ha or approximately $31.6 \%$ of the total area (Table 3). This results in having most of the field plots allocated to stratum 2 (38 of 66 field plots). On the other hand, only two field plots were established in stratum 5.

Summaries of tree attributes (mean tree density and basal area) of $P$. euphratica forests were calculated only for live trees and presented in Table 4. As to be expected, the estimated mean tree density (number of trees per hectare) increases with crown cover percentage; it is lowest for stratum 2 and highest for stratum 5 (59.3 and 467.0 trees per hectare, respectively). On the other hand, the precision of the estimate generally decreases with increasing crown cover percentage, as indicated by the increase in estimated SE. This leads to wide $95 \%$ CI for strata 4 and 5 (owing to a low number of degrees of freedom and consequently a large $t$ value). The $95 \%$ CI for stratum 2 (42.6 to 75.9 trees per hectare) indicates that the estimated mean tree density is significantly smaller than the estimates from the other strata. The estimated $\mathrm{CV} \%$ shows that there is huge variability in tree density between field plots in stratum $2(85.2 \%)$ as compared to the other strata. This variability is indicated by the large difference between the minimum and maximum values of tree density for stratum 2 (8.0 and 199.0 trees per hectare, respectively) and large standard deviation of tree density (50.7 trees per hectare) that is similar to the mean value. Stratum 5 has the lowest estimated $\mathrm{CV} \%$, indicating that the two field plots are relatively similar to each other in terms of tree density $(8.6 \%)$.

Estimated total number of trees in each stratum $\left(\hat{\tau}_{h}\right)$ has an opposite trend (Table 4$)$. Stratum 5 has

Table 3 Crown cover strata and number of phase 1 photo-plots $\left(n_{h}\right)$ and phase 2 field plots $\left(m_{h}\right)$

\begin{tabular}{|c|c|c|c|c|c|c|}
\hline \multirow[t]{2}{*}{ Stratum } & \multirow[t]{2}{*}{ Crown cover $(\%)$} & \multicolumn{2}{|c|}{ Phase 1} & \multicolumn{2}{|c|}{ Phase 2} & \multirow{2}{*}{$\frac{\text { Estimated area (ha) }}{a_{h}}$} \\
\hline & & $\overline{n_{h}}$ & Stratum size $(\%)$ & $\overline{m_{h}}$ & Stratum size $(\%)^{\mathrm{a}}$ & \\
\hline 1 & 0 & 87 & 31.6 & - & - & 70.26 \\
\hline 2 & $>0-10$ & 113 & 41.1 & 38 & 60.1 & 91.26 \\
\hline 3 & $>10-30$ & 56 & 20.4 & 21 & 29.8 & 45.23 \\
\hline 4 & $>30-50$ & 13 & 4.7 & 5 & 6.9 & 10.50 \\
\hline 5 & $>50$ & 6 & 2.2 & 2 & 3.2 & 4.85 \\
\hline Total & & 275 & 100.0 & 66 & 100.0 & 222.1 \\
\hline
\end{tabular}

${ }^{\text {a Phase }} 2$ stratum sizes are calculated only for strata 2 to 5 , as no field plots were sampled in stratum 1 . The estimated area in hectare is calculated for each stratum from Eq. 5. Phase 2 stratum size for strata 2 to 5 is calculated as the percent proportion of $n_{h}$ to $\sum_{h=2}^{5} n_{h}=188$. These estimates are used as a guideline to allocate the number of phase 2 field plots $\left(m_{h}\right)$ to each stratum. 
Table 4 Summary of estimated means and totals of tree density and basal area for each stratum and study sites

\begin{tabular}{|c|c|c|c|c|c|c|c|c|c|}
\hline & \multicolumn{6}{|c|}{ Estimated mean per ha $\left(\bar{y}_{h}\right)$} & \multicolumn{3}{|c|}{ Estimated total $\left(\hat{\tau}_{h}\right)$} \\
\hline & Mean & SE & Lower $95 \% \mathrm{CI}$ & Upper $95 \%$ CI & $\mathrm{CV} \%$ & Total & $\overline{\mathrm{SE}}$ & Lower $95 \% \mathrm{CI}$ & Upper $95 \% \mathrm{CI}$ \\
\hline \multicolumn{10}{|l|}{ Tree density } \\
\hline Stratum 2 & 59.3 & 8.2 & 42.6 & 75.9 & 85.2 & $5,409.9$ & 750.2 & $3,889.5$ & 6930.3 \\
\hline Stratum 3 & 146.7 & 18.7 & 107.7 & 185.7 & 58.4 & $6,634.8$ & 845.3 & $4,871.7$ & 8397.9 \\
\hline Stratum 4 & 367.9 & 67.7 & 179.9 & 555.9 & 41.1 & $3,836.0$ & 711.0 & $1,889.0$ & 5837.0 \\
\hline Stratum 5 & 467.0 & 28.3 & 107.4 & 826.5 & 8.6 & $2,264.7$ & 137.3 & 520.7 & 4008.7 \\
\hline Study sites & 81.8 & 8.1 & 65.8 & 97.8 & - & $18,170.0$ & 1794.2 & $14,612.0$ & 21728.0 \\
\hline \multicolumn{10}{|c|}{ Basal area $\left(\mathrm{m}^{2}\right)$} \\
\hline Stratum 2 & 4.3 & 0.6 & 3.0 & 5.5 & 86.0 & 389.7 & 57.0 & 273.8 & 505.6 \\
\hline Stratum 3 & 6.9 & 0.9 & 5.0 & 8.8 & 59.8 & 312.5 & 40.7 & 227.5 & 397.6 \\
\hline Stratum 4 & 15.2 & 2.9 & 7.2 & 23.2 & 42.7 & 159.2 & 30.2 & 75.3 & 243.1 \\
\hline Stratum 5 & 18.8 & 4.0 & 0.0 & 69.6 & 3.0 & 91.1 & 19.4 & 0.0 & 337.6 \\
\hline Study sites & 4.3 & 0.4 & 3.5 & 5.1 & - & 952.8 & 88.8 & 775.1 & 1130.5 \\
\hline
\end{tabular}

The means and the totals are presented with their corresponding SE, lower and upper 95\% CI, and CV\%. Observe that all study sites estimates of tree density and basal area include estimations from stratum 1, which have means and standard errors of zero

the lowest total number of trees, while stratum 3 has the highest $(2,264.7$ and 6,634.8 trees, respectively). The SE for the total number of trees for stratum 5 is distinctly smaller than other strata. The observed trend resulted from incorporating estimated areas of strata into calculating the total number of trees (refer to Eqs. 6 and 10). Thus, the small estimated area of stratum 5 (4.85 ha in Table 3) influences the total estimates of the stratum, even though the estimated mean and its standard error are relatively large.

The trends of estimated stratum mean and total, their corresponding standard errors, and coefficient of variation for basal area per hectare generally follow that of tree density. Stratum 2 has the highest $\mathrm{CV} \%(86.0 \%)$ due to the large range in mean basal area per hectare $\left(0.1-16.3 \mathrm{~m}^{2} / \mathrm{ha}\right)$. The large SE of the mean basal area per hectare for stratum $5\left(4.0 \mathrm{~m}^{2} / \mathrm{ha}\right)$ causes the lower bound $95 \% \mathrm{CI}$ to be $0.0 \mathrm{~m}^{2} / \mathrm{ha}$. The low precision of the estimates for stratum 5 is due to the small number of field plots $\left(m_{h}=2\right)$. The estimated mean basal area per hectare for the study sites equals that of stratum 2, a reasonable result as indicated by Eq. 3. The estimated mean basal area per hectare for the study sites includes the mean value for stratum 1 (which is consistently $\bar{y}_{1}=0$ ) and is also a function of the estimated weights $n_{h} / n$ of each stratum (which is stratum size in percentage for phase 1 in Table 3 ). The fact that the empty stra- tum 1 and the low density stratum 2 occupy $72.7 \%$ of the total area $(31.6 \%$ and $41.1 \%$, respectively) makes the estimated mean basal area per hectare for the whole study sites relatively low.

\section{Discussion}

Sampling issues

In our study, stratification increases the efficiency of the fieldwork when compared to unrestricted simple random sampling or systematic sampling. In phase 1 , approximately $31.6 \%$ of the study sites (70.26 ha) are classified into stratum 1 (no P. euphratica crown cover), implying that this stratum does not require field plot installation. Excluding this area from phase 2 sampling allows us to allocate all the effort to measure field plots that actually contain individuals of $P$. euphratica. This is a considerable gain in efficiency in terms of field work compared to other sampling designs without stratification in which there is a high possibility of including some field plots that are without $P$. $\mathrm{eu}$ phratica trees. Thus, using double sampling for stratification (DDS) is justified and appropriate in this study.

By using the moving window approach, there is also the possibility of pixelwise prestratification because each pixel has received a stratum 
classification from the beginning; thus, stratified random sampling (StRS) could have then been used. However, this alternative procedure entails a major complication in this context in that it rests on the assumption that the poplar crown cover mask is perfectly accurate. Experience in this study shows that there were considerable difficulties to automatically distinguish the cover of shrub species, particularly Tamarix ramosissima, from $P$. euphratica trees. Even though it may be manageable to produce a poplar crown cover mask for the entire study sites by employing visual interpretation and manual delineation, it is laborious and most likely error prone and of lesser quality. On the other hand, DSS allows us to focus the refinement of the poplar crown cover mask on the selected photo-plots in the phase 2 sample, which constitute only a small fraction of the entire area. This increases the accuracy of the manual delineation of $P$. euphratica crown cover, and altogether, it is more efficient and less labor intensive. In the meantime, a poplar crown cover mask is still available over the entire study sites to provide an estimate of total $P$. euphratica crown cover.

Another sampling issue is the size difference between photo-plots and field plots for stratum 4 and 5 because vegetation stratification based on cover is a function of the size of the reference areas on which cover is observed (Kleinn 2001). Although the field plots for the two strata are smaller than the photo-plots in size, the crown cover percentage of the plots are estimated from the corresponding photo-plots with a radius of $20 \mathrm{~m}$. This may lead to a slight discrepancy between crown cover percentage observed in the field and that derived from photo-plots and possible misclassification if the discrepancy is large. Overall, the size difference sampling issue would reduce the performance of the post-stratification slightly.

A convenient feature of DDS is that we do not need to address border plots correction procedures in the field because the plots are assigned unambiguously to one stratum only. Thus, a slopover of border plots into neighboring strata is not an issue. However, a side effect of this convenience is that one sample plot may in fact contain sections of different density strata and be consequently assigned to an intermediate stratum.
For example, if one half of a particular plot has a crown cover of $55 \%$ (stratum 5) and the other half is empty $(0 \%$, thus stratum 1$)$, then the plot would have been assigned to stratum 2. This is certainly a suboptimal strata assignment for some plots, but it may only occur to few plots in our study such that the loss of efficiency can be expected to be minimal.

Estimating change is crucial in monitoring the progress of desertification and the health status of $P$. euphratica forests. Such monitoring would require repeated observations on the same field plots. There are numerous approaches to extend double sampling for stratification to achieve this objective. One of the possibilities is incorporating sampling with partial replacement (SPR; Ware and Cunia 1962) into phase 2 of DSS as suggested by Bickford et al. (1963) and Scott and Köhl (1994). Very generally, SPR is a design that combines temporary and permanent plots; at the next remeasurement, some of the initial plots are remeasured while some new plots are added (Scott 1998).

\section{Attributes of $P$. euphratica forests}

Photo-plots of strata 1 and 2 are primarily distributed away from the Tarim River, whereas plots of strata 4 and 5 are closer to the river course (Fig. 4). Thus, tree density decreases with increasing distance from the river course. This result agrees with a census study in this area (Cai et al. 2008) and with another study at various locations of the Tarim River (Halik et al. 2008). Although this study does not consider any spatial trend, the corresponding study from Cai et al. (2008) concluded that the regeneration in our area (trees with height less than $3.0 \mathrm{~m}$ ) occurred predominantly within $50 \mathrm{~m}$ of the river course. They also concluded that the majority of $P$. euphratica trees had heights between 3.0 and $9.0 \mathrm{~m}$ and that they were distributed mostly within $300 \mathrm{~m}$ from the river bed. This gradient in tree height distribution is likely related to groundwater. On average, the groundwater level drops gradually from 5.0 to $9.5 \mathrm{~m}$ between 20 and 1,200 $\mathrm{m}$ away from the river, affecting tree density, height distribution, and height growth (Halik et al. 2008). The height growth of $P$. euphratica does not exceed $0.2 \mathrm{~m} /$ year when the groundwater level is 
between 4.0 and $6.5 \mathrm{~m}$ (Halik et al. 2008). Therefore, the small crown length observed in this study is most likely affected by broken or dead treetops as well as the groundwater level conditions. Many $P$. euphratica trees in the study sites develop secondary crowns. How and why secondary crowns are formed is poorly known; it could be the residual primary crown from dieback due to decreasing groundwater level. On the other hand, it could be crown re-establishment for some trees that might benefit from the "ecological restoration" project.

Stratification is one of the most widely used variance reduction techniques in sampling (Holt and Smith 1979). This is mainly achieved through proportional allocation of sample sizes where larger strata and/or more heterogeneous strata receive more samples. The large estimated coefficient of variation (CV\%) and range indicate that both tree density and basal area per hectare are highly variable within stratum 2 . By allocating $60.1 \%$ of the sampling effort $\left(m_{h}=38\right.$ field plots) to this stratum, the precisions of the estimated mean tree density and basal area per hectare are increased to a certain extent. The high variability in strata 2 and 3 (CV\% of $85-86 \%$ and $58-60 \%$, respectively) suggests that more sampling effort could further increase the precision of these estimates. Alternatively, one could define more strata with narrower intervals at lower crown cover percentages to possibly achieve greater homogeneity of the field plots. Both greater homogeneity and clear differences in strata mean values lead to higher precision of estimates (Thompson 2002; Husch et al. 2003). The low precision of estimates for strata 4 and 5 are largely due to lower sampling sizes. A possible solution would be to increase the number of field plots for the two strata (given practical constraints).

Other applications of double sampling for stratification

In this study, the advantages of high-resolution satellite image and double sampling for stratification are used to quantify the current characteristics of the $P$. euphratica forests along the lower reaches of the Tarim River. However, we foresee promising application to other sparse tree populations such as trees outside the forest
(TOF), in particular where agroforestry systems are abundant. Trees outside the forest, defined by FAO (2002) as "trees growing outside the forest and not belonging to the category of forests, forest lands, or other wooded land," are recognized for their multi-purpose and multi-use potential and have received attention from conservationists as important elements in biological conservation and biological corridors. FAO (2002) provides a comprehensive discussion on TOF in terms of definitions, management practices and policies. Nonetheless, inventories of TOF have been rare and disparate (FAO 2002). Only a few countries have TOF monitoring systems in place andcontrary to forest inventories - there is no general recommended methodology for TOF inventory and assessment to date (see also Kleinn 2000). Countries have employed diverse sampling and plot designs to sample TOF based on local conditions and the need for integration into larger inventory projects (FAO 2002). However, a common theme among the various designs is the use of maps, aerial photographs, or satellite imageries. TOF have similar distributions as that of $P$. euphratica forests, i.e., isolated trees distributed, for example, among agricultural fields or dense gallery forests along the rivers or edges of the agricultural fields. Hence, the procedures outlined in this study may be recommended (with modifications) as an option of an inventory design for monitoring TOF.

\section{Conclusions}

There has been a constant interest in studying the physiology and ecology of $P$. euphratica, but there is no precedent study that applies probability sampling to inventorying this resource in Argan area or the larger surrounding region. The advantages of probability sampling from this study are many folds. For example, the choice of grid size $(100 \mathrm{~m})$ and field plot sizes $(r=20$ or $15 \mathrm{~m})$ in this study may not be the optimum for highly heterogeneous $P$. euphratica forest. For efficiency, one would ideally choose the type and size of field plots that sample proportionally to the variance of the stand parameters of interest, e.g., stand density (Husch et al. 2003). Furthermore, optimum 
allocation determines the number of field plots for each stratum according to its variability and area, thus achieving a given precision with the smallest possible sample size (Husch et al. 2003). Hence, the information on the precision of estimates in Table 4 is particularly indispensable and could assist decision making and facilitate designing future studies.

Acknowledgements We express our utmost gratitude toward Prof. Dr. Birgit Kleinschmit and Prof. Dr. Johannes Küchler from TU Berlin and Dr. Umut Halik from Xinjiang University for engaging us in the EVAStar project and providing the corresponding author the opportunity to participate in the fieldwork in Xinjiang, China. We are very grateful to Wolfgang Straub and Frank Paproth for the help and the involvement in the project and the fieldwork. In addition, we especially would like to thank Alishir Kurban, Cai Fuyan, Duan Hanming, Jörg Schulz, Maryam Abdu, Wang Shanshan, and many other researchers and graduate students from the Chinese Academy of Sciences Xinjiang Branch and Xinjiang University for their dedication in completing the fieldwork. We also like to express our gratitude to Andrew Bluhm and an anonymous reviewer for providing comments that greatly improve the manuscript. Last but not least, our thanks are given to the staff of EVAStar for the permission to use the data and the Quickbird satellite images for analysis.

Open Access This article is distributed under the terms of the Creative Commons Attribution Noncommercial License which permits any noncommercial use, distribution, and reproduction in any medium, provided the original author(s) and source are credited.

\section{References}

Bickford, C. A. (1952). The sampling design used in the forest survey of the northeast. Journal of Forestry, 50(4), 290-293.

Bickford, C. A., Mayer, C. E., \& Ware, K. D. (1963). An efficient sampling design for forest inventory: The northeastern forest resurvey. Journal of Forestry, 61(11), 826-833.

Cai, F. Y., Halik, U., Arkin, A., Abdumijit, A., Coenradie, B., \& Kleinschmit, B. (2008). Tree height distribution and density of Populus euphratica forest along the Argan section in the lower reaches of Tarim River. Ecology and Environment, 17(3), 1086-1090.

Chinese Committee for Implementing UN Convention to Combat Desertification (CCICCD) (1997). China country paper to combat desertification. Beijing: China Forestry Publishing House.

Chen, Y. N., Zilliacus, H., Li, W. H., Zhang, H. F., \& Chen, Y. P. (2006). Ground-water level affects plant species diversity along the lower reaches of the Tarim river,
Western China. Journal of Arid Environments, 66(2), 231-246.

Chojnacky, D. C. (1998). Double sampling for stratification: A forest inventory application in the interior west. USDA Forest Service Rocky Mountain Research Station. Research Paper RMRS-RP-7, Ogden, UT, USA.

Cochran, W. G. (1977). Sampling techniques. New York: Wiley.

FAO (1983). Provisional methodology for assessment and mapping of desertification. Rome, Italy: Food and Agriculture Organization of the United Nations and United Nations Environment Programme, Global Environmental Monitoring System.

FAO (2002). Trees outside forests: towards a better awareness. In R. Bellefontaine, S. Petit, M. Pain-Orcet, P. Deleporte, J.-G. Bertault (Eds.), FAO conservation guide 35 (pp. 1-216). Rome: FAO.

Gao, S. W., Wang, B. F., Zhu, L. Y., Wang, J. H., \& Zhang, Y. G. (1998). Monitoring and evaluation indicator system on sandy desertification of China. Scientia Silvae Sinicae, 34(2), 1-10.

Geist, H. (2005). The causes and progression of desertification. Burlington: Ashgate Publishing Company.

Halik, U., Zheng, C., Shu-zheng, L., Coenradie, B., \& Kleinschmit, B. (2008). Study on the height volume growth of Populus euphratica and spatial distribution in lower reaches of Tarim River, Xinjiang. Journal of Arid Land Resources and Environment, 22(5), 187-191.

Holt, D., \& Smith, T. M. (1979). Post stratification. Journal of the Royal Statistical Society Series A (General), 142(1), 33-46.

$\mathrm{Hu}, \mathrm{P}$. X. (2003). A probe into the status and counter measures of sandy desertification in China. Scientia Silvae Sinicae, 39(5), 140-146.

Huang, S., \& Siegert, F. (2006). Land cover classification optimized to detect areas at risk of desertification in North China based on SPOT VEGETATION imagery. Journal of Arid Environments, 67(2), 308-327.

Husch, B., Beers, T. W., \& Kershaw, Jr., J. A. (2003). Forest mensuration. New York: Wiley.

Institute of Landscape Architecture and Environmental Planning (2007). Automatic mapping of vitality of alluvial forests in arid regions using very highresolution satellite data-Tugay Forests at the lower reaches of Tarim River, Xinjiang, China. http://www. geoinformation.tu-berlin.de/index.php?id=141\&L=1. Accessed 25 April 2009.

Kleinn, C. (2000). On large area inventory and assessment of trees outside forests. Unasylva 200 (2000/1), 51, 3-10.

Kleinn, C. (2001). A cautionary note on the minimum crown cover criterion in forest definitions. Canadian Journal of Forest Research, 31(2), 350-356.

Li, H. Q. (2004). The desertification research process. World Forestry Research, 17(1), 11-14.

Lohr, S. L. (1999). Sampling: Design and analysis. Pacific Grove: Duxbury Press.

Lu, Q. (2001). Improving regional eco-environment by combating desertification. World Forestry Research, 14(6), 33-40. 
Ma, L. P., Han, G. Q., \& Li, Y. (1996). The application of TM imagery to investigating desertification land in Hexi area. Journal of Desert Research, 16(4), 401-406.

Neyman, J. (1938). Contribution to the theory of sampling human populations. Journal of the American Statistical Association, 33(201), 101-116.

Satterthwaite, F. E. (1946). An approximate distribution of estimates of variance components. Biometrics Bulletin, 2(6), 110-114.

Scott, C. T. (1998). Sampling methods for estimating change in forest resources. Ecological Applications, $8(2), 228-233$.

Scott, C. T., \& Bechtold, W. A. (1995). Techniques and computations for mapping plot clusters that straddle stand boundaries. Forest Science Monograph, 31, 46-61.

Scott, C. T., \& Köhl, M. (1994). Sampling with partial replacement and stratification. Forest Science, 40(1), 30-46.

Sun, B. P., \& Fang, T. Z. (2001). Desertification in China and its control. In S.-W. Breckle, M. Veste, W. Wucherer (Eds.), Sustainable land use in deserts. Berlin, Germany: Springer.

Thompson, S. K. (2002). Sampling. New York: Wiley.

UNEP (1997). United Nations convention to combat desertification in those countries experiencing serious drought and/or desertification, particularly in Africa. Geneva, Switzerland: UNEP's Information Unit, CCD/95/1.

Wang, R. H., \& Fan, Z. L. (1998). Study on land desertification in the Argan region at the lower reaches of Tarim River with remote sensing and GIS. Journal of Remote Sensing, 2, 137-142.

Wang, J. H., Zhang, Z. Q., Jia, B. Q., \& Meng, F. R. (2003). Classification system for desertification and its quantitative assessment methodology in China. Forestry Studies in China, 5(3), 42-48.

Ware, K. D., \& Cunia, T. (1962). Continuous forest inventory with partial replacement of samples. Forest Science Monograph, 3, 1-40.

Williams, M. S. (2001). Comparison of estimation techniques for a forest inventory in which double sam- pling for stratification is used. Forest Science, 47(4), $563-576$.

Williams, M. S., \& Schreuder, H. T. (1995). Documentation and evaluation of growth and other estimators for the fully mapped design used by FIA: A simulation study. Forest Science Monograph, 31, 26-45.

$\mathrm{Wu}, \mathrm{B}$. (2001). Current status, dynamics and causes of desertification in China. World Forestry Research, 14(2), 195-202.

Wu, W., Wang, X. Z., \& Yao, F. F. (1997). Applying remote sensing data for desertification monitoring in the $\mathrm{Mu}$ Us Sandy Land. Journal of Desert Research, 17(4), 415-420.

Yang, X., Zhang, K., Jia, B., \& Ci, L. (2005). Desertification assessment in China: An overview. Journal of Arid Environments, 63(2), 514-531.

Zhang, Y. (2002). Problems in the fusion of commercial high resolution satellite as well as Landsat 7 images and initial solutions. In: The International Archives of the Photogrammetry, Remote Sensing and Spatial Information Sciences, Vol. XXXIV, part 4, pp 6. http:// www.isprs.org/commission4/proceedings02/paper.html. Accessed 2 May 2009.

Zhang, Y. M., Chen, Y. N., \& Pan, B. R. (2005). Distribution and floristics of desert plant communities in the lower reaches of Tarim River, southern Xinjiang, People's Republic of China. Journal of Arid Environments, 63(4), 772-784.

Zhou, J. X., Han, X. W., Kong, F. B., \& Wang, X. (2003). A study on the development of combating desertification in China. World Forestry Research, 16(2), 42-47.

Zhu, Z. (1985). Status and trend of desertification in northern China. Journal of Desert Research, 5(3), 3-11.

Zhu, Z., \& Wang, T. (1990). An analysis on the trend of land desertification in northern China during the last decade based on examples from some typical areas. Acta Geographica Sinica, 45, 430-440.

Zhu, Z., \& Wu, H. (1998). Study on combating desertification/land degradation in China. Beijing: China Environmental Science Press. 